\title{
Development of Fly Ash Composite Binder and Optimization of Slurry Ratio
}

\author{
Qingfeng ZHUO ${ }^{\mathrm{a}, 1}$, Lei BA ${ }^{\mathrm{a}}$, Jing WANG ${ }^{\mathrm{a}}$ and Qifeng WANG ${ }^{\mathrm{b}}$ \\ ${ }^{a}$ Department of Resource Engineering, Ordos Vocational College, Ordos, Inner \\ Mongolia, China \\ b Shendong Coal Group, Yulin, Shanxi, China
}

\begin{abstract}
In view of the high cost of cement filling, the new cementitious materials are developed by using solid waste resources. Firstly, on the basis of material physicochemical analysis, the fly ash composite cementation ratio test and optimization test are carried out to determine the optimal ratio. Then, the filling body strength and pipeline transportation characteristics test are carried out to analyze they influence law. Finally, the genetic algorithm is used to optimize the slurry ratio. The results show that the strength of cemented backfill increases linearly with the increase of slurry concentration; The slump and bleeding rate of slurry decrease with the increase of slurry mass fraction, and increase with the decrease of binder sand ratio, the optimal proportion of fly ash (FA) based composite binder is w(FA): w(clinker): w (desulfurized gypsum (DG)): w (slag powder $(\mathrm{SP}))=40: 12: 12: 36$; The optimum slurry ratio is $1: 4$ of binder/sand and $72 \%$ of concentration.
\end{abstract}

Keywords. Filling mining, fly ash, slag, composite binder, optimization, filling slurry

\section{Introduction}

Mining industry is a traditional rough industry. For filling mining, the research shows that the cost of cementitious materials accounts for about $70 \%$ of the filling cost. At present, most mines use cement as filling cementing agent, but the cost of cement is high and the mine benefit is low. Therefore, it is urgent to develop filling cementitious materials with low cost and excellent properties [1-2]. Using solid waste resources to develop new filling cementitious materials can not only reduce the cost of filling materials, but also realize industrial application by using solid waste resources [3]. Compared with cement, the new cementitious material is a kind of cementitious material which uses alkali, salt or composite activator to excite a class of potentially active pozzolanic materials such as slag, fly ash, steel slag, red mud and coal gangue, etc. [4-5], so as to make it hydraulic, On the premise of meeting the requirements of mine strength and rheology, the optimization of slurry ratio not only significantly reduces the cost, but also innovates the filling technology and process to a certain extent [6-7].

${ }^{1}$ Corresponding Author, Qingfeng ZHUO, Department of Resource Engineering, Ordos Vocational College, Ordos, Inner Mongolia, China; Email: 359839732@qq.com. 


\section{Analysis of Physicochemical Properties of Test Materials}

FA and SP were used as active materials, DG and clinker were used as activators to develop binder. The chemical composition of the test material was analyzed by XRF, and the results are shown in table 1. The tailings are used as aggregate. The particle size gradation analysis of the materials, the results are shown in figure 1. the characteristic particle is calculated. It can be seen that the content of SP, FA, DG, clinker and tailings +200 mesh is $93 \%, 75.6 \%, 94.78 \%, 78.14 \%$ and $21.74 \%$ respectively.

Table 1. Analysis results of chemical composition of test materials.

\begin{tabular}{lllllllllll}
\hline Materials & $\mathrm{SiO}_{2}$ & $\mathrm{Al}_{2} \mathrm{O}_{3}$ & $\mathrm{Fe}_{2} \mathrm{O}_{3}$ & $\mathbf{C a O}$ & $\mathbf{M g O}$ & $\mathbf{M n O}$ & $\mathrm{TiO}_{2}$ & $\begin{array}{l}\text { Activity } \\
\text { coefficient }\end{array}$ & $\begin{array}{l}\text { Alkalinity } \\
\text { coefficient }\end{array}$ & $\begin{array}{l}\text { Quality } \\
\text { coefficient }\end{array}$ \\
\hline SP (\%) & 32.02 & 10.19 & 1.31 & 40.99 & 9.33 & 0.24 & 2.82 & 0.318 & 1.192 & 1.724 \\
FA (\%) & 56.16 & 21.02 & 5.17 & 8.90 & 2.34 & - & 1.27 & 0.374 & 0.145 & 0.562 \\
DG (\%) & 5.68 & 1.48 & 1.91 & 44.51 & 4.06 & 0.02 & 0.10 & & & \\
Clinker (\%) & 21.46 & 4.44 & 4.69 & 64.69 & 2.89 & - & - & & & \\
\hline
\end{tabular}

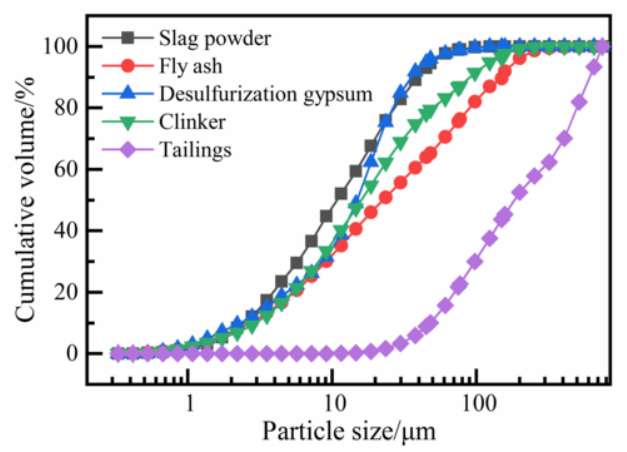

Figure 1. The particle size distribution curve of test material.

\section{Proportioning Test of Fly Ash Composite Binder}

\subsection{Test Scheme and Results}

The test scheme of the activator ratio of fly ash-based cement for tailings aggregate is determined as follows: orthogonal test with $3^{3}$ is adopted, including $40 \%-50 \%$ of the FA, $10 \%-20 \%$ of clinker, $8 \%-12 \%$ of DG, the test adopts $1: 4$ of binder/sand $(\mathrm{B} / \mathrm{S})$ and $70 \%$ concentration $\left(C_{w}\right)$ to prepare slurry, after mixing evenly, pour to $7.07 \mathrm{~cm} \times 7.07 \mathrm{~cm} \times 7.07 \mathrm{~cm}$ mold, standard curing. Measure the strength after curing to the corresponding age. The specific test plan and results are shown in table 2 .

\subsection{Analysis of Test Results}

In order to determine the influence weight of each test factor on strength and the optimal proportion of fly ash composite binder, the range analysis of test results in table 2 is carried out, and the results are shown in figure 2, It can be seen that the order of the 
influence of various factors on the $7 \mathrm{~d}$ and $28 \mathrm{~d}$ strength of backfill is $w(\mathrm{FA})>w($ clinker $)>w(\mathrm{DG})$; Range analysis shows that the optimal proportion of $7 \mathrm{~d}$ strength is $w(\mathrm{FA}): w($ clinker): $w(\mathrm{DG}): w(\mathrm{SP})=40: 12: 10: 38$, while the optimal proportion of $28 \mathrm{~d}$ strength is $w(\mathrm{FA}): w($ clinker $): w(\mathrm{DG}): w(\mathrm{SP})=40: 16: 8: 36$.

Table 2. Orthogonal test results of the ratio of fly ash composite binder.

\begin{tabular}{lllllll}
\hline \multirow{2}{*}{ NO. } & FA (\%) & Clinker $(\%)$ & DG $(\%)$ & SP (\%) & \multicolumn{2}{c}{ Compressive strength (MPa) } \\
\cline { 6 - 7 } & & 12 & 8 & 40 & 1.57 & $\mathbf{7 d}$ \\
\hline A1 & 40 & 16 & 10 & 34 & 1.73 & 2.82 \\
A2 & 40 & 12 & 28 & 1.27 & 3.63 \\
A3 & 40 & 20 & 10 & 33 & 1.48 & 3.47 \\
A4 & 45 & 12 & 12 & 27 & 1.22 & 2.56 \\
A5 & 45 & 16 & 8 & 27 & 1.07 & 2.99 \\
A6 & 45 & 20 & 12 & 26 & 1.17 & 3.29 \\
A7 & 50 & 12 & 8 & 26 & 1.18 & 2.07 \\
A8 & 50 & 16 & 10 & 20 & 0.73 & 2.50 \\
A9 & 50 & 20 & & &
\end{tabular}
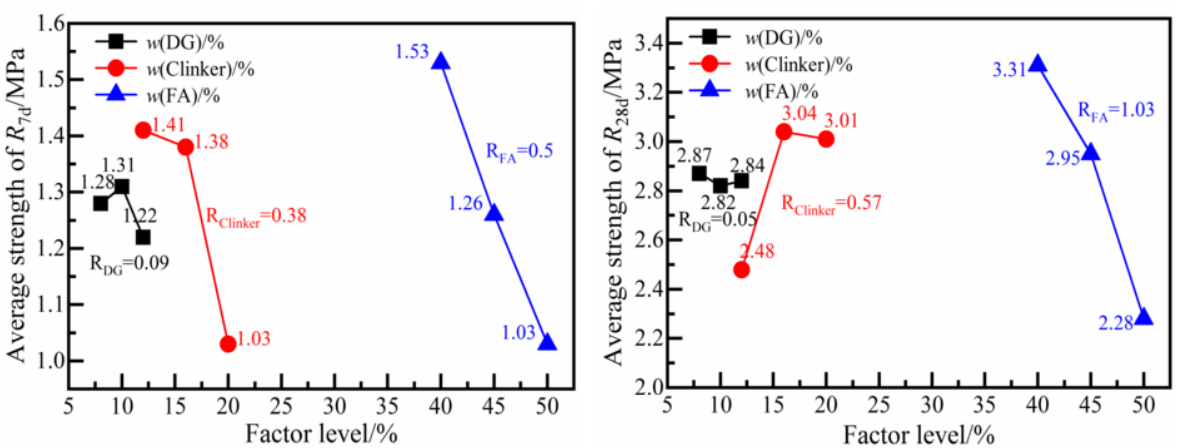

Figure 2. Range analysis results of orthogonal test on the ratio of fly ash composite binder.

\subsection{Proportioning Optimization Test of Fly Ash Composite Binder}

In order to determine the proportion of fly ash composite binder, on the premise of meeting the requirements of mine filling, the proportion of binder is optimized by reducing the amount of cement clinker. The orthogonal test is carried out by fixing the $w(\mathrm{FA})=40 \%$, reducing the $w$ (clinker) $=8 \%-12 \%$, increasing the $w(\mathrm{DG})=10 \%-14 \%$. The optimization test is also carried out by using the $\mathrm{B} / \mathrm{S}$ is $1: 4$, and the concentration is $70 \%$. The specific test scheme and test results are shown in table 3 . It can be seen that the $7 \mathrm{~d}$ strength is greater than $1.5 \mathrm{MPa}$, which meets the mine requirements, and the $28 \mathrm{~d}$ strength is greater than $2.5 \mathrm{MPa}$ except for $\mathrm{B} 1$ and $\mathrm{B} 3$; And through the range analysis, it is concluded that the optimal proportions of $7 \mathrm{~d}$ and $28 \mathrm{~d}$ are $w(\mathrm{FA}): w$ (clinker): $w(\mathrm{DG}): w(\mathrm{SP})=40: 12: 12: 36$. The material cost is $156 \mathrm{yuan} / \mathrm{t}$, which is $58.9 \%$ lower than the 42.5 cement. 
Table 3. Orthogonal test results of optimum proportion of fly ash composite binder.

\begin{tabular}{|c|c|c|c|c|c|c|c|}
\hline \multirow{2}{*}{ No. } & \multirow{2}{*}{ FA (\%) } & \multirow{2}{*}{ Clinker (\%) } & \multirow{2}{*}{ DG (\%) } & \multirow{2}{*}{ SP (\%) } & \multicolumn{2}{|c|}{ Strength (MPa) } & \multirow{2}{*}{$\begin{array}{l}\text { Cost } \\
\left(\text { Yuan.t }{ }^{-1}\right)\end{array}$} \\
\hline & & & & & $7 d$ & 28d & \\
\hline B1 & 40 & 8 & 10 & 42 & 1.65 & 2.31 & 150 \\
\hline B2 & 40 & 8 & 12 & 40 & 1.72 & 2.62 & 147 \\
\hline B3 & 40 & 8 & 14 & 38 & 1.71 & 2.34 & 145 \\
\hline B4 & 40 & 10 & 10 & 40 & 1.67 & 2.57 & 155 \\
\hline B5 & 40 & 10 & 12 & 38 & 1.76 & 2.78 & 152 \\
\hline B6 & 40 & 10 & 14 & 36 & 1.60 & 2.55 & 150 \\
\hline B7 & 40 & 12 & 10 & 38 & 1.69 & 3.01 & 160 \\
\hline B8 & 40 & 12 & 12 & 36 & 1.67 & 2.97 & 156 \\
\hline B9 & 40 & 12 & 14 & 34 & 1.79 & 2.73 & 155 \\
\hline \multicolumn{5}{|c|}{ P.O 42.5} & 3.08 & 5.15 & 380 \\
\hline \multicolumn{8}{|c|}{ Cost $/$ yuan $\mathrm{t}^{-1}: \mathrm{FA}=120$, Clinker $=410, \mathrm{DG}=34.5, \mathrm{SP}=156$} \\
\hline
\end{tabular}

\section{Proportioning Test of Fly Ash Composite Binder and Tailings Filling Slurry}

\subsection{Strength Test of Cemented Backfill}

In view of the low-cost fly ash composite binder, the tailings are used as aggregate to carry out the strength test of backfill with different binder/sand and concentration. The specific test scheme is as follows: the $\mathrm{B} / \mathrm{S}$ is $1: 4,1: 6$ and $1: 8$, and the $C_{w}$ is $72 \%, 74 \%$, $76 \%$ and $78 \%$. The results are shown in figure 3 . It can be seen that the strength of backfill increases linearly with the increase of concentration; When the ratio of cement to sand is $1: 4$, the slurry concentration increases to $76 \%$, and the growth rate of $7 \mathrm{~d}$ and $28 \mathrm{~d}$ strength increases; When the $\mathrm{B} / \mathrm{S}=1: 4$, the $7 \mathrm{~d}$ strength and $28 \mathrm{~d}$ strength of the backfill with $C_{w}=72 \% \sim 78 \%$ are all greater than $1.5 \mathrm{MPa}$ and $2.5 \mathrm{MPa}$ respectively; When $\mathrm{B} / \mathrm{S}=1: 6$, the $7 \mathrm{~d}$ strength and $28 \mathrm{~d}$ strength of backfill with $C_{w}$ greater than $76 \%$ also meet the mine requirements.
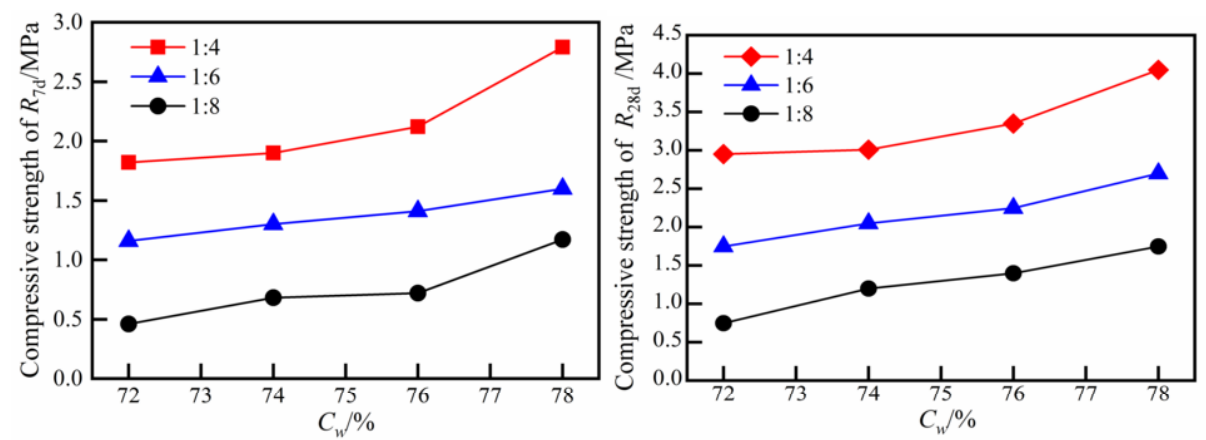

Figure 3. Strength of backfill of fly ash composite cementitious material and tailings.

\subsection{The Pipeline Transportation Characteristics Test of Filling Slurry}

Slump tube and bleeding rate tube were used to measure the slump and bleeding rate of filling slurry, and the test data were recorded and analyzed. The test results are shown 
in figure 4. It can be seen that the slump and bleeding rate of slurry decrease with the increase of slurry mass concentration. Taking the $\mathrm{B} / \mathrm{S}=1: 4$ as an example, when the $C_{w}$ increases from $72 \%$ to $78 \%$, the slump and bleeding rate decrease by $5.7 \%$ and $76.5 \%$ respectively; However, the pipeline characteristics increase with the decrease of the ratio of cement to sand. Taking the $C_{w}=72 \%$ as an example, the slump and bleeding rate increased by $2.7 \%$ and $50 \%$ respectively when the B/S decreased from $1: 4$ to $1: 8$.
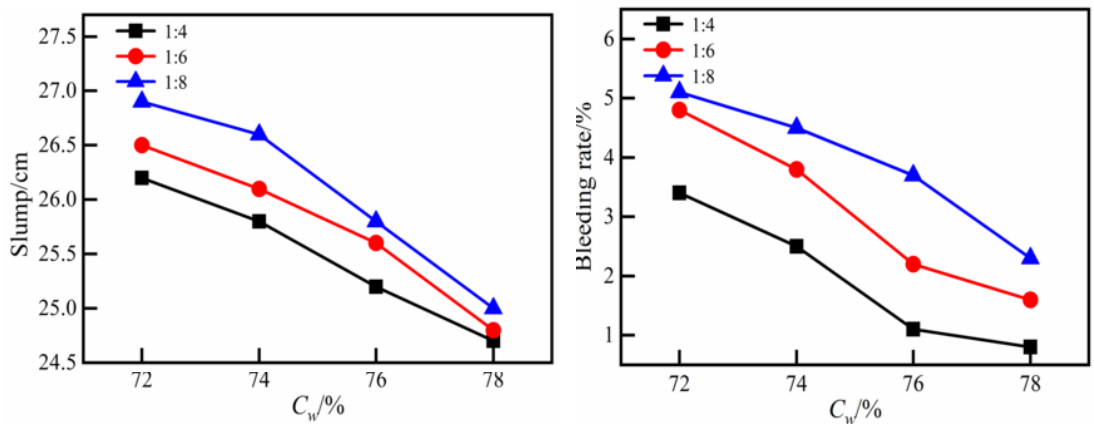

Figure 4. Test results of pipeline transportation characteristics of filling slurry.

\subsection{Multi-objective Optimization of Filling Slurry Ratio}

On the premise of meeting the requirements of mine filling, the filling cost should be reduced as much as possible. Therefore, it is necessary to optimize the filling slurry ratio in order to obtain the optimal filling slurry ratio. The mine requires that the strength of $7 \mathrm{~d}$ and $28 \mathrm{~d}$ is not less than $1.5 \mathrm{MPa}$ and $2.5 \mathrm{MPa}$ respectively, while the reasonable range of slump is $15 \sim 30 \mathrm{~cm}$, and the ideal value is $18 \mathrm{~cm}$ and the bleeding rate is less than $10 \%$ [8-9]. According to the test results, $7 \mathrm{~d}$ and $28 \mathrm{~d}$ strength can be regarded as benefit index, while slump, bleeding rate and filling cost can be regarded as cost index. In this paper, under the condition of meeting the filling requirements, taking the cementitious material dosage $\left(x_{1}\right)$, tailings dosage $\left(x_{2}\right)$ and water dosage $\left(x_{3}\right)$ of filling slurry per unit volume as independent variables, the functional relationships between backfill $7 \mathrm{~d}$ strength $\left(R_{7 \mathrm{~d}}\right), 28 \mathrm{~d}$ strength $\left(R_{28 \mathrm{~d}}\right)$, slump $(T)$, bleeding rate $(M)$ and filling cost $(P)$ and independent variables were established by genetic programming. Among them, magnesium slag cementitious material is 156 yuan/t, tailings freight is 2 yuan/t, and water unit price is $1.5 y u a n / t$. The optimization objective is: $R_{7 d} \geq 1.5 \mathrm{MPa}$, $\mathrm{R}_{28 \mathrm{~d}} \geq 2.5 \mathrm{MPa}, M, T$ and $P$ are minimum; The constraint conditions are as follows: $1: 8 \leq\left(x_{1} / x_{2}\right) \leq 1: 4,72 \% \leq C_{w}\left(x_{1}+x_{2}\right) /\left(x_{1}+x_{2}+x_{3}\right) \leq 78 \%$.In the multi-objective genetic algorithm, there are five objective functions, namely $R_{7 \mathrm{~d}}\left(x_{1}, x_{2}, x_{3}\right), R_{28 \mathrm{~d}}\left(x_{1}, x_{2}, x_{3}\right)$, $M\left(x_{1}, x_{2}, x_{3}\right), T\left(x_{1}, x_{2}, x_{3}\right)$ and $P\left(x_{1}, x_{2}, x_{3}\right)$, among $P\left(x_{1}, x_{2}, x_{3}\right)=156 \times x_{1}+2 \times x_{2}+1.5 \times x_{3}$, The other objective functions are established by fitting the experimental results, that is, the optimization objective is:

$$
\left\{\begin{array}{l}
\max R_{7 \mathrm{~d}}\left(x_{1}, x_{2}, x_{3}\right) \\
\max R_{28 \mathrm{~d}}\left(x_{1}, x_{2}, x_{3}\right) \\
\min T\left(x_{1}, x_{2}, x_{3}\right) \\
\min M\left(x_{1}, x_{2}, x_{3}\right) \\
\min P\left(x_{1}, x_{2}, x_{3}\right)
\end{array}\right.
$$



follows:

According to the mine requirements, the constraint conditions are determined as

$$
\left\{\begin{array}{l}
R_{7 d} \geq 1.5 \\
R_{28 d} \geq 2.5 \\
\frac{1}{8} \leq \frac{x_{1}}{x_{2}} \leq \frac{1}{4} \\
72 \% \leq \frac{x_{1}+x_{2}}{x_{1}+x_{2}+x_{3}} \leq 78 \%
\end{array}\right.
$$

Then, Matlab genetic algorithm is used for optimization. Because Matlab solves the minimum problem by default, the benefit index needs to be negative, so the total objective function is constructed as follows [10]:

$$
F=w_{1} \cdot T+w_{2} \cdot M+w_{3} \cdot P-w_{4} \cdot R_{7 d}-w_{5} \cdot R_{28 d}
$$

where: $w_{1}, w_{2}, w_{3}, w_{4}$ and $w_{5}$ are the weights of $7 \mathrm{~d}, 28 \mathrm{~d}$ strength, slump, bleeding rate and filling cost respectively. For convenience of calculation, they are all taken as 0.2.

The optimal ratio of filling slurry per unit volume can be obtained by using genetic algorithm. The optimal ratio of filling slurry of unit volume is obtained, which is $296 \mathrm{~kg} / \mathrm{m}^{3}$ of cementitious material, $1184 \mathrm{~kg} / \mathrm{m}^{3}$ of tailings, $575 \mathrm{~kg} / \mathrm{m}^{3}$ of water, namely, the $\mathrm{B} / \mathrm{S}=1: 4$ and $C_{w}=72 \%$. The results showed that the strength of $7 \mathrm{~d}, 28 \mathrm{~d}$, slump and bleeding rate is $1.89 \mathrm{MPa}, 3.08 \mathrm{MPa}, 26.0 \mathrm{~cm}$ and $3.6 \%$ respectively, and all indexes met the mine requirements.

\section{Conclusion}

(1) The results of the range analysis of the orthogonal test of the fly ash-based composite binder show that the factors affecting the strength of $7 \mathrm{~d}$ and $28 \mathrm{~d}$ are all $\mathrm{w}(\mathrm{FA})>\mathrm{w}($ clinker $)>\mathrm{w}(\mathrm{DG})$; and it is determined by the optimization test of the ratio The optimized ratio is: $w(\mathrm{FA}): w($ clinker $): w(\mathrm{DG}): w(\mathrm{SP})=40: 12: 12: 36$.

(2) The test results of mortar strength and slurry transportation characteristics show that the strength of cemented backfill increases linearly with the increase of slurry concentration; When the ratio of $\mathrm{B} / \mathrm{S}=1: 4$, the $C_{w}=76 \%$, and the growth rate of $7 \mathrm{~d}$ and $28 \mathrm{~d}$ strength increases; The slump and bleeding rate of slurry decrease with the increase of slurry mass concentration, and increase with the decrease of the ratio of cement to sand.

(3) The genetic algorithm is used to optimize the filling slurry ratio with multi-objective, and the optimization model is established with the requirements of strength and slurry working characteristics of the mine as constraints. The lowest cost scheme meeting the requirements of filling strength and slurry pipeline transportation characteristics is obtained, that is, the fly ash composite binder, the $\mathrm{B} / \mathrm{S}=1: 4$, and the $C_{w}=72 \%$, the $7 \mathrm{~d}, 28 \mathrm{~d}$ strength, slump and bleeding rate are $1.89 \mathrm{MPa}, 3.08 \mathrm{MPa}, 26.0 \mathrm{~cm}$ and $3.6 \%$ respectively. 


\section{Reference}

[1] Yang X B 2020 Study on Collaborative Preparation of Filling Materials with Low Quality and Multi-solid Wastes and Their Pressure Drop in Pipeline Transportation (Beijing: University of Science and Technology Beijing).

[2] Yin B C 2013 Research on cemented filling technology with fine-grained full tailings for a Shandong mine Metal Mine (04) 57-60.

[3] Ma X M, Ni W and Xu D 2018 Research progress of backfill binders prepared with industrial solid wastes Metal Mine (04) 11-17.

[4] Wei W, Yang Z Q and Gao Q 2013 Cementing action of neotype whole-tailing cementitious material Journal of Building Materials 16 (5) 881-887.

[5] Zhu L P, Ni W, Huang D, et al. 2011 Research on whole-tailings paste and paste-like backfilling material with red mud Mining Research and Development (11) 175-178.

[6] Zhang Q L, Li X P and Yang W 2013 Optimization of filling slurry ratio in a mine based on back propagation neural network Journal of Central South University (Science and Technology) 44 (7) 2867-2874.

[7] Zhou K P and Gu D S 2001 Genetic optimization design of the cement-sand ratio of tailings consolidated filling in Anqing copper mine Metal Mine (07) 11-13.

[8] Zhao G Y, Ma J, Peng K, et al. 2013 Mix ratio optimization of alpine mine backfill based on response surface method Journal of University of Science and Technology Beijing (5) 559-565.

[9] Fall M, Benzaazoua M and Saa E G 2008 Mix proportioning of underground cemented tailings backfill Tunnelling \& Underground Space Technology 23 (1) 80-90.

[10] Liu Z X, Gong Y C and Li X B 2017 Study on the backfilling material properties based on fractal theory and BP neural network Gold Science and Technology 25 (02) 38-44. 